\title{
DEBATES
}

\section{Diálogo sobre el concepto de "estrategia" de la clase obrera}

\author{
Paula Varela - Nicolás Iñigo Carrera
}

Como planteáramos en el primer número de Archivos, la puesta en pie de una revista que aborda la historia del movimiento obrero y la izquierda implica asumir el reto del debate acerca de diferentes conceptualizaciones que hacen a la definición misma del objeto de estudio y al modo en que nos posicionamos ante él, en el trabajo historiográfico y también en el presente. En este número presentamos un debate entre Paula Varela y Nicolás Iñigo Carrera que surgió de una serie de comentarios y posterior diálogo ${ }^{1}$ en ocasión de la tercera edición (corregida y aumentada) de La estrategia de la clase obrera $1936 .^{2}$ En dicha oportunidad, el intercambio se centró no en una crítica general al libro sino en una reflexión particular sobre el uso que Iñigo Carrera realiza del concepto de estrategia y las consecuencias que éste tiene en el propio desarrollo de su investigación sobre la huelga general de 1936. Para la publicación del debate Archivos propuso como metodología que la crítica de Paula Varela fuera enviada por escrito con antelación, documento a partir del cual Iñigo Carrera elaboró su respuesta con posterioridad.

$$
* * *
$$

1. El encuentro se llevó a cabo en el marco del taller coordinado por Agustín Santella y Lucas Poy en el Instituto de Investigaciones Gino Germani de la UBA.

2. Imago Mundi, 2012, Buenos Aires.

(Archivos, año III, $\mathrm{n}^{\circ}$ 6, pp. 155-175) 


\section{La estrategia objetiva, ¿ilusión teleológica del historiador?}

\section{Paula Varela}

En el texto que sigue el lector no encontrará una reseña o un debate historiográfico general sobre La estrategia de la clase obrera 1936, sino el esfuerzo por poner a discusión la lógica argumental de la tesis central de esa obra. Ese esfuerzo está impulsado por un doble interés. Un interés teórico que pretende esquivar la contraposición abstracta de esquemas generales para discutir, a través de la problematización de análisis situados, las posibilidades del marxismo para dar las mejores explicaciones posibles de los procesos históricos y sus resultados. Y un interés político de buscar en el pasado una fuente de lecciones para el presente y el futuro. Agradezco a Nicolás Iñigo Carrera su aliento a que expusiera en forma escrita las críticas realizadas oralmente.

\section{Un libro que hay que leer}

Hay al menos tres motivos por los que leer La estrategia.... como trabajo historiográfico logra reconstruir no sólo el momento de la huelga general de 1936, sino más que eso. Configura una instantánea de esa ciudad de Buenos Aires, la composición social de sus barrios, las posiciones estratégicas del proletariado distribuidas en el territorio, el clima de época expresado a través de tangos y milongas de circulación cotidiana. El relato permite observar los flujos de circulación de ramas de producción, de oficios, de generaciones, que esa ciudad tenía. El libro permite atravesar Mataderos, Liniers, Devoto, Paternal, Flores, recorrer la historia de su gestación y encontrarse allí, en la mañana del 7 de enero de 1936, con las barricadas, los enfrentamientos con la policía, los piquetes espontáneos de mujeres, jóvenes y vecinos, los cruces de solidaridad entre individuos desconocidos pero mancomunados en la lucha, las sorpresas y hasta las valentías de los niños envueltos en clima de revuelta. Vivir, en definitiva, la apropiación de la ciudad por las masas. En una historiografia, incluso la de tradición marxista en la que se inscribe este libro, que ha caído muchas veces en cierto desdén por la geografia, La estrategia... recupera la importancia del espacio para mostrar una ciudad de Buenos Aires como campo de batalla, como teatro de operaciones. Pero además la instantánea de esta Buenos Aires en una batalla de clase, se contrapone con la postal, muchas veces fabricada, de la Buenos Aires desclasada, pacificada, territorio de una clase media cuya circulación está signada únicamente por el 
comercio. En sentido opuesto, La estrategia... le devuelve a Buenos Aires su carácter obrero. ${ }^{3}$

El segundo motivo, es por el periodo que toma para investigar: la década del 30. En los últimos diez o quince años se han multiplicado el número de investigaciones sobre esa época ${ }^{4}$ y de ellas resulta, además de algunas refutaciones a sentidos comunes en la academia, la evidencia de lo necesario que sigue siendo profundizar en el estudio de esos años. No sólo por su indisociable relación con "los orígenes del peronismo", sino también porque esta década permite ver que, al igual que sucede a nivel internacional, es imposible comprender la historia del movimiento obrero en Argentina de forma disociada de la historia de la izquierda. La década del 30 es la evidencia de que esta disociación sería "mutilar la comprensión de ambos sujetos", ${ }^{5}$ al mismo tiempo que señala el punto de inflexión en que los caminos del movimiento obrero y la izquierda se bifurcan sin volverse jamás paralelos. La estrategia... resulta también una invitación a la reflexión acerca de esta relación, incluso porque algunos presupuestos teóricos que criticaremos más adelante, obligan a subir la guardia para evitar los mecanicismos objetivistas y los politicismos voluntaristas.

Por último, hay que destacar lo que constituye, quizás, el rasgo principal de este libro: la elección de Iñigo Carrera de "entrar" a la historia a través del concepto de estrategia. Entrada que en el uso que hace el autor del concepto resulta polémica pero que, en su propia apuesta, es una crítica a las formas en que la historiografia (y también la sociología) dominante en la academia, analizan la clase obrera. La recuperación de la noción de estrategia es, antes que nada, el señalamiento de que estamos ante un "sujeto contendiente". Eso que resulta obvio es, sin embargo, necesario de ser resaltado en la medida en que, al igual que en las lecturas historiográficas, en el nuevo auge de estudios sobre la clase obrera que comenzó en los últimos años, ésta vuelve a aparecer una vez más como un sujeto pasivizado al que el Estado le otorga un "nuevo modelo de relaciones laborales" que se ha configurado en los gabinetes gubernamentales y nunca en el terreno de la lucha de clases. La noción de estrategia introduce una cuña en ese pensamiento institucionalista y obliga a volver a hacer foco en el enfrentamiento como terreno de constitución de la clase obrera y terreno en que se realizan posibilidades históricas determinadas. Pero esta noción es, además, una

3. Al respecto, véase Hernán Camarero, "Consideraciones sobre la historia social de la Argentina urbana en las décadas de 1920 y 1930: clase obrera y sectores populares", Nuevo Topo, $\mathrm{n}^{\circ} 4$, septiembre-octubre de 2007.

4. Véanse los trabajos de Hernán Camarero, Diego Ceruso y Fernando López Trujillo.

5. Véase "Introducción" de Archivos N¹. 
afrenta contra las miradas que reducen a la clase obrera a un puro sujeto social. Ya sea desde un punto de vista "autonomista" o "movimientista" (que han cobrado peso hacia fines de los 90 y principios de los 2000 de la mano del "espontaneísmo de la derrota"), o desde un punto de vista "institucionalista" (históricamente ligado a la mirada estatal sobre la clase obrera y por ende, a la mirada burguesa), las ciencias sociales académicas vienen eludiendo el análisis de la clase obrera en su potencialidad de sujeto politico, en su potencialidad de sujeto dirigente. La noción de estrategia abre la puerta a la restitución de ese "derecho" que los trabajadores y trabajadoras conquistaron en las primeras décadas del siglo XX, y pone sobre la mesa el problema de las formas a través de las cuales la clase obrera puede hacerse clase dirigente del conjunto de los explotados y oprimidos. Por último, la noción de estrategia introduce un dedo en otra llaga de la producción académica: la de la idea del antagonismo (el enfrentamiento) como dinámica de articulación y clave explicativa para la comprensión de la totalidad social. Si la táctica es la conducción de las operaciones aisladas, la academia ha mostrado una desmedida "pasión por la táctica" en la medida en que se profesionaliza en el estudio cada vez más parcializado de acciones forzadas a cobrar sentido per se, de luchas disociadas, de fracciones que se explican a sí mismas. La pregunta por la estrategia incomoda al individualismo (metodológico y político) y abre una grieta a través de la cual comprender el encadenamiento de esas operaciones aisladas. Al hacerlo introduce la pregunta por la posibilidad de que la clase obrera se constituya en clase hegemónica, en sujeto capaz del ejercicio del poder.

\section{Las contradicciones}

La pregunta central de libro de Iñigo Carrera es cuál es la estrategia de la clase obrera que se hace observable en la huelga general del 7 y 8 de enero de 1936. Este interrogante está explícitamente inscripto en un interés intelectual (y político) mayor: el de profundizar la explicación de la adhesión de la clase obrera argentina al peronismo, rastreando en los enfrentamientos sociales que ésta libró durante la década del 30 y 40 (particularmente la huelgas generales desde 1930 hasta 1946), los antecedentes de esa adhesión. Esta búsqueda retrospectiva sobrevuela el conjunto del libro y es, quizás, parte de la explicación de sus contradicciones.

Lo primero que surge es la curiosidad acerca de cómo se dispone el autor a rastrear la estrategia de la clase obrera. Esta pregunta (teóricometodológica) es central en la medida en que su respuesta es, en sí misma, una definición acerca de a qué se refiere Iñigo Carrera con ese concepto. A diferencia de lo que implicaría reconstruir las diversas 
estrategias puestas en juego en la clase obrera durante un período de tiempo determinado (que llevaría a analizar al menos cuatro variables: los programas expuestos en materiales y discursos de las diversas corrientes, grupos, partidos; la relación de dichos programas con las características de la "formación económico-social"; el peso real de dichas corrientes en la clase obrera -para sopesar sus chances de influir efectivamente en los enfrentamientos y moldear los resultados-; y, sobretodo, la contraposición de estos programas con la práctica concreta puesta de manifiesto no en enfrentamientos aislados sino en el ordenamiento de enfrentamientos de modo tal que ésta vuelva observable sus objetivos), la propuesta de observar la estrategia de la clase obrera obliga a preguntarse cómo ésta se vuelve distinguible, reconocible, diferenciable de las diversas estrategias en la clase obrera. La respuesta del libro al respecto es clara: la estrategia de la clase obrera en 1936 es la que triunfó. Y ese triunfo se habría materializado según el autor en el acto del $1^{\circ}$ de mayo de 1936 organizado por la CGT. ${ }^{6}$ Acto que, por sus convocantes y por su programa, vuelve visible que la estrategia de la clase obrera en dicho período es la de su incorporación al régimen institucional.

He aqui lo que consideramos el problema central del que se derivan una serie de otros problemas: la equiparación de estrategia con resultado. Esta identificación que transforma el resultado de un enfrentamiento, de un encuentro (en este caso la huelga general del 36), en una meta, abre la puerta a una visión teleológica de la historia que introduce una serie de contradicciones en el texto que, siendo de origen teórico, terminan refractando en el propio análisis historiográfico del proceso.

La primera contradicción es que la amalgama de resultado con objetivo hace que la propia definición de estrategia ingrese en un terreno resbaladizo tensada por dos concepciones. Por un lado, una concepción que, basándose en la clásica cita de Engels, hace hincapié en la historia como un resultado "que nadie quería". ${ }^{7}$ Por otro lado, una concepción

6. Como veremos más adelante, la consideración del acto del $1^{\circ}$ de mayo de 1936 como el resultado de la huelga responde a una necesidad de la lógica de argumentación del autor (y de la tesis que el autor intenta sostener).

7.“(...) la historia se hace ella misma de tal modo que el resultado final proviene siempre de conflictos entre el gran número de voluntades individuales, cada una de las cuales está hecha a su vez por un cúmulo de condiciones particulares de existencia. Hay pues innumerables fuerzas que se entrecruzan, una serie infinita de paralelogramos de fuerza que dan origen a una resultante: el hecho histórico. A su vez, éste puede considerarse como producto de una fuerza que, tomada en su conjunto, trabaja inconsciente e involuntariamente. Pues el deseo de cada individuo es obstaculizado por el de otro, de lo que resulta algo que nadie queria." (Engels, citado en pie de página 17, cita 5). Si bien no se trata aquí de debatir sobre concepciones del materialismo histórico, hay que decir que la elección de esta cita por parte de Iñigo Carrera no sólo es un recorte limitado de las posiciones de los "clásicos" respecto de la historia (al que 
que define el resultado como producto de un determinado "uso de los encuentros para alcanzar el objetivo de la guerra" $\mathrm{y}$ obliga a preguntarse por el sujeto de dicho uso. Acerca de esta tensión, Iñigo Carrera afirma:

Podría objetarse que al plantear de esta manera la existencia de estrategias que ordenan los enfrentamientos, se está haciendo referencia, implícitamente, a que en todo momento existe algún tipo de conducción de la lucha, lo que, en apariencia, contradeciria la afirmación anterior acerca de que el desarrollo de la lucha no es producto de ninguna voluntad individual. Pero no hay tal contradicción: siempre hay alguna conducción de la lucha, conducción que no es individual. Encontrar el ordenamiento en los enfrentamientos sociales solo nos estará señalando la meta y el camino para alcanzar esa meta que se ha dado una clase social en determinado momento histórico. (p.18)

Y más adelante agrega, “El movimiento 'espontáneo' es la estrategia que se da 'naturalmente' la clase obrera y un momento necesario de su proceso de formación" (p. 21). Así las cosas, la tarea historiográfica que se propone el autor consiste en reconstruir, a partir de un determinado resultado y retrospectivamente, ese movimiento necesario. La pregunta por la estrategia parece ser entonces una forma (historiográfica) de reconstruir una "necesidad histórica" que se ha puesto de manifiesto (se ha desplegado) en el encadenamiento del accionar de la clase obrera en un determinado momento histórico. Este armado conceptual obliga a una serie de interrogantes. ¿Es equiparable esta definición de estrategia a la expresión (bajo la forma de una meta) de lo que Engels denomina como la "fuerza que, tomada en su conjunto, trabaja inconsciente e involuntariamente"? ¿Puede hablarse entonces de una "estrategia inconsciente o involuntaria" de la clase obrera como expresión de la necesidad histórica? La respuesta a esta pregunta es afirmativa: “... esos enfrentamientos se ordenan siguiendo una estrategia, no importa el grado de desarrollo de la conciencia que se tenga de ella" (p.24). He aquí una idea de estrategia que resulta dificil de sostener o, en el mejor

podría contraponerse la también clásica frase de Marx en La sagrada familia acerca de que "la historia no hace nada"), sino que es un recorte ampliamente discutido en la bibliografia marxista, como puede observarse, entre otros, en el muy productivo texto de Perry Anderson sobre el "debate" entre E.P. Thompson y Althusser. Véase Teoría, politica e historia. Un debate con E.P. Thompson, Buenos Aires, Siglo XXI, 2012. 8. "Si recordamos que el desarrollo de esa lucha ha sido considerado el 'desarrollo de la guerra civil', siguiendo la teoría clásica podemos considerar que la estrategia es el uso de los encuentros para alcanzar el objetivo de la guerra" (página 18, nota 7). 
de los casos, abre dudas sobre su productividad teórica en la medida en la que aparece como un intento de incorporar un elemento subjetivo a una concepción objetivista de la historia. La estrategia, que aparecería como una especie de "enlace" entre las necesidades estructurales del capital y las acciones de la clase obrera, no opera como categoria analítica que permita explicar la relación entre la determinación y la acción en un momento histórico concreto, sino como entrada metodológica del historiador que permite ordenar retrospectivamente una secuencia de acciones que están determinadas en términos absolutos por la estructura económica. La estrategia se vuelve así una ilusión teleológica del historiador.

Reforzando esta perspectiva, el autor termina de armar el cuadro en las conclusiones:

Si en ese momento histórico el objetivo de la clase obrera argentina era entrar al sistema, necesitaba formar o participar de la formación de una fuerza democrática. Y este es el objetivo, no explícito, quizás no conciente para todos los que participaban de la huelga, pero que surge del análisis del hecho. (p. 325)

En sintesis, el razonamiento del autor respecto de su pregunta de investigación parece ser: dado que con el peronismo la clase obrera consolidó un proceso de ciudadanización (resultado fáctico), y dado que para llevar adelante cualquier proceso de ciudadanización es necesario participar de la formación de una "fuerza democrática" (presupuesto teórico-político del autor), por ende, la estrategia de la clase obrera en el 36 fue la formación de una fuerza democrática aunque ella misma no supiera que esa era su meta. Bajo este razonamiento la noción de estrategia (que constituye el corazón de la investigación) se desdibuja, y en su lugar va ganando potencia la idea de necesariedad histórica que aparece como evidente leída con el diario del 45 (lo que le otorga, además, al peronismo un carácter de necesaria fatalidad: el peronismo como la estrategia inconsciente de la clase obrera argentina).

A partir de aquí se despliega una segunda contradicción en el texto, la que se da entre esta noción de estrategia y la importancia teórica que el autor otorga a la lucha (y dentro de ella, particularmente a las huelgas generales) como proceso de constitución de las clases y de su conciencia. Esta contradicción se hace visible en el texto en la disociación entre la descripción de la huelga y la interpretación de su resultado. Veamos. El proceso concreto, el hecho, según la define el propio autor, es una huelgademostración con elementos de huelga-insurrección, movilización de masas, acciones callejeras, choque armado con la policia y muertos de ambos bandos, en el que predomina una estrategia de superación del 
sistema. ${ }^{9}$ Más aún, según Iñigo Carrera es la estrategia de superación del sistema la que va ganando a otros sectores urbanos que se suman a la huelga o bien activamente, o bien con una solidaridad pasiva que se percibe en el clima general de apoyo a los manifestantes. Esta caracterización puede encontrarse en su detalle en el excelente capítulo 9 que describe la preparación y desarrollo de la huelga general el día 7 , pero también en los capítulos 12, 13 y 14 en los que se exponen las opiniones de las distintas fracciones organizadas que participan de la huelga, como así también de las dos CGT, el PS y varios diarios comerciales. La reconstrucción que hace el autor basada en un serio trabajo de fuentes permite tener una visión equilibrada de la envergadura de la propia huelga general metropolitana por el impacto que ésta produce tanto entre sus impulsores como entre sus detractores. El componente común de todas estas opiniones es la sorpresa por la masividad de la huelga, la incorporación de sectores no directamente afectados por la convocatoria (realizada por los obreros de la construcción en paro desde hacía dos meses y por el Comité de Defensa y Solidaridad con la huelga de la construcción que aglutinaba 68 sindicatos más), y la violencia de las acciones callejeras y los enfrentamientos con las fuerzas represivas que hicieron retroceder a la policía, haciendo que los huelguistas y la población adherente se adueñaran temporariamente de un sector de la ciudad. Es esta configuración la que permite hablar de "elementos de insurrección". Las declaraciones de las dos CGT (Catamarca e Independencia) elogiando la valentía de una huelga que no secundaron y advirtiendo claramente a la patronal de la construcción que era mejor "ceder algo para no perder todo", es una muestra contundente del peligro de desborde institucional que la propia huelga presentó (ese peligro hizo que el poder ejecutivo de la nación preparara al Ejército para intervenir aunque no llegó a hacerlo). Sin embargo, luego de estas descripciones, a la hora de exponer su caracterización del resultado del proceso, el autor afirma que éste expresa una clara estrategia de incorporación en el sistema institucional que se plasma en la convocatoria del $1^{\circ}$ de mayo de 1936.

Esta tensión entre proceso y resultado es quizás uno de los desafios más importantes que propone la propia huelga del 36 al investigador en la medida en que obliga a desentenderse de toda linealidad y auscultar las contradicciones del objeto de su investigación. ¿Cómo explica Iñigo Carrera que habiendo cobrado fuerza durante el transcurso de la huelga la otra estrategia, ${ }^{10}$ el resultado del proceso sea un claro triunfo de la

9. Véase p. 329.

10. "Otra estrategia plantea la utilización de las instituciones vigentes y las luchas reivindicatorias como camino para ganar fuerza, teniendo como meta la superación 
estrategia? En el camino que toma el autor para resolver este problema vuelve a aparecer una fuerte idea de necesariedad histórica: la explicación de por qué se impuso la estrategia de incorporación al sistema no surge del análisis del propio conflicto y su puesta en relación con la dinámica de la relaciones de fuerzas configuradas previamente, sino de una correspondencia entre la estrategia de incorporación al sistema institucional y la "tendencia dominante en el momento histórico: momento ascendente de la lucha de la clase obrera, como vimos en el capítulo 3, pero que dificilmente pueda ser considerado como de revolución proletaria" (331). Es decir, luego de una detallada descripción del enfrentamiento que asume rasgos insurreccionales en la metrópoli, lo que define su resultado es que este enfrentamiento se desarrolla en un "momento de expansión del capitalismo en extensión más que en profundidad" (p. 332) y que a un momento de esas características se corresponde una estrategia de incorporación al sistema. El objeto de análisis (la lucha) queda desdibujado como parte de la determinación de su propio resultado y éste aparece dictado de antemano por el "momento histórico" del capitalismo en Argentina.

De esta afirmación llaman la atención varias cuestiones:

a) La generalidad de la noción de "momento histórico" y la ausencia de una argumentación acerca de por qué ese "momento" negaría la posibilidad de una estrategia de superación del sistema (o, dicho al revés, por qué se correspondería necesariamente con una estrategia de integración al sistema). Si bien una teoria de correspondencia entre momentos (¿estadios?) de desarrollo del capitalismo y estrategias de la clase obrera (teoría ampliamente debatida dentro del marxismo como "etapismo") trasunta el conjunto del texto, ésta no está desarrollada explícitamente ni en el capítulo de exposición del problema (capítulo teórico), ni en los capítulos 3 y 4 de descripción del contexto histórico. Es recién en las conclusiones que esta concepción etapista aparece con más claridad, aunque sin problematización ni desarrollo pese a ser un debate de primer orden entre los marxistas:

Estas dos estrategias (incorporarse al sistema o transformarlo radicalmente, NdeA) están siempre presentes a lo largo de la historia de la clase obrera. Pero en cada momento histórico se presentan con pesos relativos y de posibilidad de realización de cada una de ellas, distintos. Históricamente se ha comprobado que el desarrollo de la primera es condición

del sistema social vigente y como métodos tanto la solidaridad y la lucha en las calles como la negociación" (p. 320). 


\section{de existencia y posibilidad de realización de la segunda. (Destacado mío) $^{11}$}

b) El carácter lineal de la deducción entre esta estrategia (concebida como necesidad histórica) y el tipo de alianza social que debe llevar adelante la clase obrera para realizarla. La explicación de la convocatoria y los oradores del acto del 1 de mayo de 1936, que es indicado por el autor como resultado de la huelga, no se deduce argumentalmente del análisis del proceso huelguístico, sino que se deriva (teóricamente) de la concepción etapista a la que Iñigo Carrera suma un nuevo presupuesto tan controvertido como no desarrollado: el de la equiparación entre frente único (como necesidad de la clase obrera de formar una alianza de clase) y frente popular (como forma histórico concreta de alianza del proletariado con sectores de la burguesía). ${ }^{12}$

c) La indeterminación acerca de si el "momento histórico" se define a nivel nacional o internacional, o cómo es la relación entre esos dos ámbitos (cuestión no menor en una obra marxista). La afirmación de Iñigo Carrera acerca de que ese "momento histórico" difícilmente pueda ser considerado como de revolución proletaria, indica más bien una visión "nacional" debido a que la década del 30 a nivel internacional fue de grandes ascensos revolucionarios y dramáticas derrotas (de lo que la muestra más contundente es la revolución española y el ascenso del nazismo), y por ende, un "momento" en el que primó la dinámica de revolución y contrarrevolución que dio paso a la Segunda Guerra Mundial.

d) La conclusión obligada de la imposibilidad del triunfo de la otra

11. Página 323, nota 3. La oración destacada resulta al menos polémica teniendo en cuenta que la primera revolución obrera triunfante rompió fácticamente con esta idea de las etapas necesarias (en la medida en que se "salteó" la "etapa" de incorporación al sistema de la clase obrera), y que el marxismo (como teoría y como movimiento politico) ha debatido largamente esa ruptura en términos teóricos, dando una de las páginas más sofisticadas de teoría revolucionaria del siglo XX, la teoría de la revolución permanente en la que León Trotsky desarrolla, a partir de la experiencia histórica, una conceptualización de la relación entre las contradicciones objetivas del desarrollo del capitalismo y el espacio para la intervención del "factor subjetivo" que estas contradicciones generan. La estrategia revolucionaria se define, justamente, a partir de calibrar esa relación. Afirmar que la historia ha comprobado la necesariedad de la etapa de "ciudadanización" como condición de posibilidad de la etapa de transformación radical del sistema requeriría, al menos, una argumentación de dicho punto de vista.

12. Esta concepción desconoce los debates que se desarrollaron entre el III y el IV Congreso de la Internacional Comunista (1921 y 1922, respectivamente), que dieron lugar a la definición de Frente Único proletario, y amalgama el concepto con la orientación de Frente Popular dictada bajo la Internacional ya estalinizada (VII Congreso, 1935) y que implicaba alianzas con los partidos de la "burguesía democrática". 
estrategia que se deriva de esta conceptualización. El "momento histórico", que es en definitiva lo que explica la estrategia de la clase obrera independientemente de la lucha de clases que sólo la vuelve visible (perdiendo todo su carácter generador de las relaciones de fuerza), explica también la derrota de la otra estrategia. La otra estrategia no podía triunfar por más que haya sido seguida por sectores de masas de la clase obrera y otras fracciones del pueblo en la huelga general. En últimas, es esta certeza teórica de la imposibilidad del triunfo de la otra estrategia la que explica la disociación que el lector encuentra entre la descripción del hecho y el análisis del resultado, y explica también porqué, en un libro dedicado a reconstruir una huelga, ésta termina teniendo una incidencia casi ${ }^{13}$ nula en la reconstrucción de la estrategia, negando en la investigación concreta el peso que se le dio a la lucha de clases en la presentación teórica.

\section{Hipótesis sobre "el problema"}

Las contradicciones señaladas más arriba pueden explicarse, al menos en parte, como consecuencia de aplicar el concepto de estrategia a la clase obrera en su conjunto. Esta aplicación termina forzando la homogeneización de una clase que el propio autor reconoce como heterogénea, pero que su elección teórica unifica en una suerte de "voluntad involuntaria" impuesta por el momento histórico.

Para aplicar la noción de estrategia al conjunto de la clase obrera, Iñigo Carrera diferencia

dos procesos distintos, aunque relacionados entre sí: 1) el que hace a los enfrentamientos que va librando una clase social y cuya meta puede conocerse observando esos enfrentamientos; 2) las distintas alternativas políticas que proponen a esa clase los distintos cuadros políticos que actúan en la sociedad, y que expresan intereses de distintas clases o fracciones sociales. (p. 23, destacado mío)

Esta distinción es completamente atendible y es una buena alerta frente a la confusión entre hacer una historia de la clase obrera y hacer una historia de las corrientes politicas que intervienen en la clase obrera. Sin embargo, lo que comienza siendo una buena alerta metodológica se transforma en un mal presupuesto teórico que postula dos procesos dis-

13. La incidencia que el autor otorga a su propio objeto de estudio en la reconstrucción de la estrategia de la clase obrera es la de haber servido para potenciar el objetivo de incorporación al sistema. La otra estrategia expresada en la huelga termina siendo, astucia de la historia mediante, un instrumento de la única estrategia posible (p. 333). 
tintos alli donde existe un único proceso, confundiendo objeto de estudio con proceso histórico real. Con el argumento de evitar la sustitución de la "historia de la clase obrera" por la "historia de los partidos o sectas", Iñigo Carrera abre la puerta a la negación de la incidencia de los partidos (y sus estrategias) en la historia como proceso. En la definición de estrategia que establece el autor se gesta una escisión entre la clase obrera y las corrientes que intervienen en ella, haciendo que el vínculo entre ambas se pierda (más allá de su enunciación) y estableciendo, de facto, una suerte de externalidad en la relación entre los partidos politicos y los objetivos que la clase obrera se propone. Las corrientes politicas operan como una suerte de actores de una tragedia cuyo guión ha sido escrito previamente. ${ }^{14}$ Esto explica la ausencia de un análisis de la incidencia que las corrientes politicas que intervienen en el proceso de la huelga del 36 tienen en la configuración del resultado. Es sintomático que la recopilación de las posiciones de las corrientes politicas durante y después del enfrentamiento no esté puesta en función de intentar comprender sus consecuencias para el propio desenlace del proceso, ${ }^{15}$ sino más bien en función de un objetivo clasificatorio.

Esto se observa, por ejemplo, en el hecho de que no haya ningún análisis de la relación entre la política de frente popular que el PC (que dirigía la FOSC y el Comité de Huelga de la Construcción) estaba implementando en Argentina por mandato de la IC (y que implicaba un acercamiento al PS y el objetivo prioritario de legalización del partido para participar en un frente electoral) y el levantamiento de la huelga en un clima que, según el propio autor, demostraba gran disposición

14. El reconocimiento de la incidencia de los partidos y corrientes politicas en la lucha de clases y sus resultados implica asumir que "la dirección de ningún modo es un simple 'reflejo' de una clase, o el producto de su propia creación libre. La dirección se forja en el proceso de los choques de las distintas clases y de las fricciones entre las diferentes capas dentro de una misma clase dada" (Trotsky, 1940, Clase, partido y dirección). Esta posición teórica (y política), lejos de cualquier subjetivismo histórico, abraza un tipo de determinismo que se deshace de los supuestos mecanicistas (de una clase homogénea con la dirección que "se merece") para meterse en el análisis situado de los enfrentamientos entre las fracciones de clases cuya heterogeneidad social explica la existencia de vanguardias, retaguardias y sectores que oscilan y que conforman distintas estrategias puestas en juego (con virulencia) en los momentos de crisis.

15. Es importante señalar aquí que el propio autor afirma que "la relación entre la estructura económica de la sociedad y la posibilidad de realización de las alternativas politicas planteadas desde y hacia la clase obrera en los años 30 es objeto de otra investigación, en curso" (p. 322). Esta auspiciosa noticia no salva sino refuerza el problema que estamos señalando: la separación teórica (y luego empírica en el propio trabajo) entre la estrategia y las estrategias de la clase obrera. Separación que hace que sean objeto de estudio de dos libros distintos. 
para el combate. Si bien en el libro hay una descripción de la política de la IC y de lo que ésta significaba para el PCA, lo llamativo es que esa descripción no asume ningún carácter de factor explicativo del desenlace de la huelga. En sentido contrario a esta búsqueda de la incidencia de la política concreta de las corrientes en el resultado del encuentro, Iñigo Carrera tiende a desarrollar el razonamiento opuesto: si la estrategia de la clase obrera era la inserción en el régimen institucional (presupuesto deducido del "momento histórico"), esto explica que el PC haya privilegiado una política legalista. Razonamiento que no sólo resulta circular en términos teóricos, sino que resulta muy dificil de sostener en términos históricos dado que la política legalista del PCA tenía poco que ver con las necesidades particulares del capitalismo en extensión de la Argentina, y mucho que ver con la calamitosa derrota de la orientación estalinista del "tercer período" y el giro hacia la política de frente popular en la IC. Es decir, el legalismo del PC era una politica independiente de las características específicas del capitalismo en Argentina, lo que refuta cualquier idea de que éste constituye una "expresión" de un "legalismo intrínseco" de la clase obrera argentina de la década del 30. Algo similar sucede ante otro hecho que resulta de gran significación durante el conflicto: la persistencia de la CGT Independencia (dirigida por los socialistas y un sector del sindicalismo) en el rechazo a convocar a la huelga general, incluso ante el segundo pedido de los organizadores, pedido realizado cuando la huelga ya se mostraba de masas y con altos grados de represión policial y enfrentamiento en las calles. Resulta dificil pensar que esta negativa no haya contribuido al evaporamiento del "sentimiento hostil" que envolvió a la ciudad en esas jornadas.

Que estos hechos, por mencionar los más llamativos, no estén puestos en relación con el resultado del enfrentamiento exhibe tres problemas en el abordaje de Iñigo Carrera: en términos teóricos muestra el papel prescindente que el autor otorga a las corrientes politicas en la lucha de clases; en términos políticos las exime de sus responsabilidades, y en términos historiográficos debilita la respuesta a la pregunta de por qué se impuso la estrategia. En síntesis, estrecha una dimensión central de la reconstrucción histórica: la posibilidad de sacar lecciones políticas. La huelga general del 36 , que es presentada por el autor como la más grande huelga de la década, es sustraída al lector como terreno de enseñanzas para el futuro, haciendo que un gran trabajo de investigación histórica se prive de una de sus grandes potencialidades. 


\section{Libertad y necesidad}

\section{Nicolás Iñigo Carrera}

Como señala Paula Varela, sus observaciones criticas fueron vertidas originalmente en un taller organizado por Agustín Santella y Lucas Poy. Esas observaciones, puestas en comparación con los comentarios formales habitualmente recibidos desde el mundo académico o con los del aventurerismo parasitario y provocador, mostraban cierta originalidad: partían de considerar a la clase obrera como "sujeto contendiente", es decir, centraban la mirada en la lucha, y por eso mi estímulo a que las pusiera por escrito. Sólo una de aquellas observaciones, que me pareció acertada, no aparece en la crítica escrita: la relativa ausencia de referencia en el libro a la cuestión nacional y el movimiento obrero en la década de $1930 .^{16}$

Puestas aquellas observaciones por escrito saltan a la vista las diferencias entre Varela y el que escribe cuando se trata de precisar qué lucha: ¿es la lucha entre las clases, librada mediante fuerzas sociales que toman la forma de alianzas de clases, determinada por el momento histórico que transita una sociedad específica, tanto en las relaciones que hacen a la producción de la vida material como en sus formas políticas e ideológicas? ¿O basta con observar la lucha entre partidos y corrientes político-ideológicas que sintetizan en sí, o al menos así se da por supuesto, la confrontación entre las clases? Conocer y explicar la estrategia de la clase obrera en un momento determinado de su historia ¿requiere conocer el grado de desarrollo de las fuerzas y relaciones productivas de la sociedad de la que forma parte, la ubicación de esa sociedad nacional en las cadenas de poder internacionales, el proceso de formación ideológica de esa clase obrera específica (la historia de sus luchas) y las alternativas politicas que se plantean desde y hacia ella? ¿O basta con remitirse a la confrontación político-ideológica dentro de la izquierda, ignorando o dando por supuestos todos los otros campos de relaciones? ¿Escribir la historia de la clase obrera es escribir la historia de un partido político o es escribir la historia de la sociedad, observada en sus confrontaciones? ¿Puede reducirse la explicación de la estrategia triunfante en la clase obrera en 1936 simplemente a la política de frente popular del Partido Comunista y la Internacional Comunista? ¿Explica esta política por qué la inmensa mayoría de la clase obrera argentina tuvo

16. Abordé ese tema en el artículo "Emancipación social y emancipación nacional en el movimiento obrero argentino", en Beatriz Rajland y Maria Celia Cotarelo, La revolución en el bicentenario. Reflexiones sobre la emancipación, clases y grupos subalternos, Buenos Aires, CLACSO-FISYP, 2009. 
como meta incorporarse al sistema institucional vigente, reformándolo profundamente pero no superándolo de raíz, poniendo en cuestión su naturaleza capitalista? Esa es la discusión de fondo. Porque, en definitiva, lo que Varela propone para conocer la estrategia de la clase obrera es comenzar por reconstruir las distintas alternativas, ${ }^{17}$ es decir centrar la mirada en los partidos, considerados como algo externo a la clase, reduciendo la estrategia a alguna de esas alternativas. El análisis de las confrontaciones sociales y su ordenamiento terminan siendo, para ella, irrelevantes; el eje del análisis debe pasar por la acción de los partidos.

Veamos ahora las observaciones que apuntan a cuestiones específicas que deben ser analizadas, para después explicitar la posición metodológica adoptada en La estategia...

Varela entiende que en el libro criticado se está equiparando estrategia a resultado. No es así. La relación entre resultado y estrategia está dada porque el ordenamiento de los enfrentamientos, y cómo se libran, está subordinado a la meta que se propone la fuerza social, y esto no significa equiparación. Por eso, salvo que se confunda estrategia, meta, fuerza social y fuerza "que trabaja inconscientemente", no hay contradicción entre afirmar que la estrategia es el ordenamiento de los enfrentamientos por una fuerza social para lograr un objetivo y afirmar que siempre existe una conducción de la fuerza; lo que no quiere decir que llegue a ese objetivo tal como se lo planteó originariamente, porque existe otra(s) fuerza(s) social(es) que la enfrenta, con su propia estrategia, y el resultado puede ser el buscado por uno u otro o el de ninguno de los dos. La referencia a una fuerza que "trabaja inconscientemente" remite al resultado del proceso histórico, no a alguna de las fuerzas sociales en pugna. Que la fuerza resultante trabaje inconscientemente no significa que los contendientes no tengan conciencia sino que el resultado no es lo que quería ninguno de ellos: las fuerzas sociales tienen una conducción y una meta, pero el resultado de la lucha entre ellas no es exactamente el buscado por ninguna de las fuerzas, aunque se aproxime más al interés de una de ellas; analizar ese resultado permite conocer quién logró conducir el proceso histórico. En ningún momento se plantea que el resultado esté predeterminado, aunque, y esto es importante, tampoco son tantas las resoluciones probables. ${ }^{18}$

17. En primer lugar, los "programas expuestos", su relación con la formación económico social, su peso dentro de la clase obrera (que no se sabe cómo se mide) y finalmente la "práctica concreta" "en el ordenamiento de los enfrentamientos" en un periodo. Es decir, los programas primero y la lucha al final.

18. Por ejemplo, descubrir todos los elementos que contribuyeron a la formación del peronismo requiere conocer la estrategia (las estrategias) que se dio la burguesia tanto frente a la clase obrera, incluyendo las confrontaciones entre las distintas alternativas planteadas por la burguesía, como con respecto a la situación internacional y 
La primera contradicción que cree encontrar Varela surge de vincular dos citas que refieren a cuestiones distintas, saltándose el par de páginas que las separan, y en las que se señala que no hay actividad humana sin conciencia, por lo que no existe un movimiento puramente espontáneo. El movimiento considerado espontáneo no es más que la estrategia que se da "naturalmente", es decir con la forma de conciencia predominante en la sociedad burguesa, la mayoría de la clase obrera. ${ }^{19}$ Pero Varela interpreta este rechazo explícito a la existencia de un movimiento espontáneo, sin conciencia ni dirección (o sea puramente mecánico), como la negación del papel de la voluntad en el proceso histórico y atribuye al libro un determinismo que no es tal. El libro de ninguna manera habla de una "estrategia inconsciente e involuntaria de la clase obrera"; en primer lugar porque, como alli se dice, no existe lo inconsciente ni lo involuntario: siempre existen grados de la conciencia, con mayor o menor aproximación al conocimiento de la realidad, y lo mismo ocurre con la voluntad, es decir sobre cómo resolver la situación percibida. Lo que sí se afirma es que el investigador puede hacer observable esa estrategia centrando el análisis en los enfrentamientos sociales librados, más allá de las afirmaciones que hagan quienes componen la fuerza. ${ }^{20}$ Lo que no puede confundirse, como afirma Varela, con las necesidades del capital.

Sin embargo, a pesar de su lectura equivocada, este punto del comentario de Varela tiene la gran virtud de traer a colación una cuestión fundamental: la "tensión" que advierte entre considerar al proceso histórico como resultante de las relaciones de fuerzas objetiva (estructura económica de la sociedad), politica y potencialmente militar, y, a la vez, considerar que existen estrategias y conducción de la lucha no es más que la manifestación en esta investigación específica de la tensión entre necesidad y voluntad, tantas veces señalada por Marx. Es verdad que en los últimos tiempos diversas corrientes historiográficas confluyen en restar toda importancia al movimiento orgánico de la estructura económica de la sociedad. Sea porque critican la historiografia de los años 60 de los grandes relatos y prefieren recortar el proceso histórico

nacional. No era ese el objetivo de este libro, centrado en conocer la estrategia de la clase obrera, y por eso no está abordado el tema en un libro, que, por cierto, no se propuso explicar el surgimiento del peronismo.

19. Esta es una sintesis demasiado apretada, porque también hay que considerar la posibilidad de que opere el "instinto de clase" apuntado por Lenin.

20. Los obreros y campesinos rusos, conducidos por los bolcheviques bajo las banderas de "pan, paz y tierra", ¿'eran plenamente conscientes de que su meta implicaba cambiar de raíz todo el sistema vigente, comenzando por las relaciones de propiedad?; la plebe que clamaba por pan y que protagonizó el inició de la Revolución Francesa, ¿era consciente de que su lucha implicaba como meta objetiva la instauración de la república burguesa? 
en compartimentos estancos (historia económica, política, cultural, etc.), sea porque apelando a la "autonomía relativa del estado" y de la política (enunciada por Engels pero con un sentido diferente) terminan absolutizando esa autonomía y considerando que puede analizarse la lucha política sin referencia a la reproducción de la vida material, sea porque consideran que el capitalismo agotó su posibilidad de desarrollar sus fuerzas productivas hace cien años, todos terminan dejando de lado el análisis del movimiento orgánico. Y así como limitar la explicación de un proceso histórico al movimiento de la estructura económica impide conocer el proceso real, eliminar este aspecto del análisis conduce al mismo resultado. Que el capitalismo como sistema económico global esté recorriendo desde fines del siglo XIX su fase de descomposición, no excluye que, a la vez, encuentre espacios para expandirse, tanto en extensión como en profundidad. ¿Cómo entender si no el llamado "proceso de industrialización por sustitución de importaciones" desarrollado en los años de que se ocupa el libro?

Es justamente ese proceso de expansión capitalista predominantemente en extensión, es decir, expandiendo las relaciones capitalistas sobre espacios donde antes no predominaban, con el consiguiente movimiento de atracción e incorporación de población a las relaciones salariales, lo que constituye la condición para el desarrollo de una política de incorporación al sistema institucional de fracciones obreras. Obviamente ese movimiento de la estructura económica no explica por sí sólo el proceso de ciudadanización, de ninguna manera novedoso pero potenciado a partir de la mitad de la década de 1940, y que hasta ese momento era conducido por las organizaciones de izquierda. Es necesario tomar en consideración el proceso de luchas políticas, las contradicciones en el seno de burguesía, incluso la disposición de fuerzas en el mundo, $y$, fundamentalmente, la lucha de los trabajadores por incorporarse al sistema institucional. Pero no puede dejarse de lado el momento que recorre el desarrollo capitalista en Argentina.

Esto nos lleva a la cuestión de la "visión teleológica de la historia" que Varela atribuye al libro; y la segunda contradicción que cree advertir. No fue necesario leer el diario de 1945 para encontrar en la huelga y acto del $1^{\circ}$ de mayo de 1936, e incluso en la misma huelga del 7 y 8 de enero, la presencia predominante de una estrategia que tenía como meta incorporarse al sistema institucional. Si bien en el momento de la lucha callejera la clase obrera confrontó con ese sistema, se colocó por fuera de él, y en ese sentido siguió "la otra estrategia", la disciplinada y unánime finalización de la huelga, siguiendo las directivas del Comité encabezado por Mateo Fossa, donde predominaban quienes apuntaban a incorporarse al sistema, muestra que esta última era la estrategia predominante (y en ese sentido la estrategia de la clase obrera). A 
diferencia de lo ocurrido en la Semana de Enero de 1919, cuando el levantamiento de la huelga por la FORA IX fue ignorado por una buena parte de la clase obrera, que asumió la continuidad de la lucha callejera impulsada por la FORA V, en enero de 1936 la protesta de la FACA y del CRRA por la finalización de la huelga general no consiguió convocar a los trabajadores. La "segunda contradicción" estuvo en la realidad misma, en la confrontación en la huelga del 7 y 8 de enero entre dos estrategias donde la que tenía como meta penetrar el sistema resultó la seguida por los trabajadores.

Todo esto está contenido en la huelga general de enero de 1936: si se observa la drasticidad y extensión de la lucha callejera, tanto en este hecho como en otros de la década, dificilmente pueda afirmarse que se trató de un período en que predominaban la conciliación de clases y la ausencia de luchas. Pero el que en determinados hechos se hiciera presente una estrategia de confrontación con el sistema institucional no invalida que la mayoría de la clase obrera organizada sindical y políticamente se planteara como meta formar parte de ese sistema y no superarlo.

Varela confunde el análisis de un proceso histórico con explicar ese proceso por su culminación. Ni siquiera considerando que el objeto de la historia es "el hecho único e irrepetible" puede dejarse de lado el proceso histórico del que el hecho forma parte. Más aún, si el objetivo es descubrir cuál es la estrategia de una clase social, descubriendo el ordenamiento de los enfrentamientos que libra, para conocer cuál es su meta, es imposible dejar de considerar los diferentes enfrentamientos que lo constituyen. Y por eso, para comprender la estrategia presente en la huelga general de enero de 1936 no puede eludirse tomar en consideración el 17 de octubre de 1945. Pero no porque en este último hecho esté la explicación. Como ya dije, en la disciplinada finalización de la huelga y de la lucha callejera, acatada sin excepción por todos los trabajadores, está ya presente la dirección que toma la lucha y que se manifiesta abiertamente el $1^{\circ}$ de mayo; aunque no hubiese existido el 17 de octubre de 1945, la estrategia de formar parte del sistema institucional hacia años que era predominante. ${ }^{21}$ No es que esa estrategia estuviera

21. Juan Carlos Torre ha realizado un ejercicio de "historia contrafáctica" a partir de imaginar el fracaso de la movilización del 17 de octubre de 1945 (Juan Carlos Torre, “¿Qué hubiese ocurrido si hubiese fracasado el 17 de octubre de 1945?”, en Santiago Senén González y Gabriel D. Lerman [comps.], El 17 de octubre de 1945. Antes, durante y después, Buenos Aires, Ediciones Lumière, 2005) y el resultado, en lo que hace al movimiento obrero, es bastante plausible: un movimiento obrero reformista, conducido por socialistas y comunistas, como en Chile y Uruguay (página 73). En otras palabras, la misma estrategia de insertarse en el sistema institucional, con un discurso de izquierda. 
"predeterminada" sino que es la resultante de las luchas libradas por la clase obrera hasta ese momento, con las que construyó su conciencia de su situación asalariada y cuál era el camino para modificarla, en las condiciones del desarrollo en extensión del capitalismo argentino; esa estrategia es la que, en ese proceso histórico, efectivamente predominó sobre la que pretendía cambiar de raíz el régimen político y social, fue la que siguió la inmensa mayoría de la clase obrera organizada y por eso puede considerarse la estrategia de la clase obrera en ese momento histórico, sin por eso desconocer la existencia de la otra estrategia y las alternativas politicas planteadas, expuestas en los capítulos 13, 14 y 15 .

Hacerse presente, e incluso ganar una batalla, no significa ganar la guerra. La otra estrategia emergió en la lucha callejera pero fue superada. Si no, se cae en una visión lineal: cada triunfo parcial es considerado indicador de la victoria final y cuando sobreviene la derrota no se la puede explicar o se acude a explicaciones ad hoc, como, por ejemplo, "la traición de los dirigentes" o "la línea política impuesta por la IC", sin explicar por qué los trabajadores siguen a esos dirigentes o a esa línea política, ni la relación de ésta con el momento histórico.

Habiendo atribuido al libro el considerar que existe una necesariedad en el desarrollo del proceso histórico y vincular esta necesariedad con las necesidades estructurales del capital, los presupuestos teórico-politicos de Varela la llevan a concluir que el libro se enmarca "vagamente" en una concepción "etapista".

Lo curioso es que el término "etapa" sólo aparece 4 veces en todo el libro y ninguna en el sentido que le atribuye Varela. ${ }^{22}$ No porque sea una concepción no asumida, sino porque no fue escrito con esa concepción. Salvo que se piense que el proceso histórico se desarrolla sin dirección alguna y que cualquier desenlace es posible en todo momento (por ejemplo, que mañana nos encontremos viviendo en una sociedad feudal o que, de pronto, amanezcamos en una sociedad socialista), debemos aceptar que ese proceso pasa por diferentes momentos históricos, término que nada tiene de vago. ¿Qué entender por "momento histórico"? Una situación, una relación de fuerzas históricamente determinada, cuyo análisis requiere de observar los distintos campos de relaciones de fuerzas, tal como están expuestas en el libro: las relaciones de fuerza políticas, es decir, de dónde viene la clase obrera, cuál es su experiencia de lucha, su conciencia de su situación y cómo resolverla, construida en 50 años de luchas (capítulos 2, 3 y 6); la relación de fuerzas objetiva existente, o sea el análisis de la estructura económica de la sociedad

22. Una vez para referirse a los pasos de la investigación (p. 13); otras dos veces en citas de otros autores (pp. 39-40 y 64) y la tercera, en su sentido literario, para caracterizar la política de la FORA (p. 320). 
(capítulos 4 y 5), y las relaciones potencialmente militares, el momento de la confrontación (capítulos 7 a 15).

Tampoco es atribuible a una concepción "etapista" señalar que la lucha económica precede a la lucha política. Aunque no siempre los obreros lograron ciudadanizarse, en todos los procesos históricos se verificó la tendencia señalada por Marx a que la lucha de los obreros por reivindicaciones inmediatas precediera a la forma politica de esa misma lucha y a la lucha por la superación del capitalismo. ${ }^{23}$ La constatación de este rasgo no significa que existan etapas preestablecidas que deban sucederse en un orden determinado, ni que sea imposible un proceso revolucionario antes de que se desarrolle un proceso de institucionalización de fracciones obreras.

¿Dónde observar esas relaciones de fuerza en esta investigación específica? La determinación del momento histórico en este libro se circunscribe al ámbito nacional: hablar de ascensos revolucionarios en España o en la China, cuando se pretende conocer la estrategia de la clase obrera en Argentina, es otra manera de eludir un trabajo de investigación sistemático, dirigido a conocer un proceso histórico específico, incluso en su relación con el proceso mundial; el crecimiento de las fuerzas contrarrevolucionarias en el mundo es también un hecho que contribuye a potenciar la alianza con fracciones burguesas y la estrategia de insertarse en el sistema vigente.

Y si observamos la realidad argentina, Varela parece creer que en enero de 1936 la revolución socialista era posible en Argentina. Pero no da ningún elemento de prueba que sustente su hipótesis. ${ }^{24}$ La derrota de esa otra estrategia ¿no debería analizarse en el marco de la instauración de una nueva situación en Argentina, que abarca desde un proceso de profunda transformación capitalista y el fin de la crisis económica abierta en 1928 hasta la resolución, al menos parcial, de la crisis de los cuadros políticos de la burguesía, y al menos de una fracción de la clase obrera, abierta en $1930{ }^{25}$ ¿Puede limitarse la explicación de esa constatación al cambio de política de la Internacional Comunista? En mi opinión esa explicación sólo es posible a partir de una mirada autocentrada en la izquierda, que deja de lado el conjunto

23. Karl Marx, Miseria de la filosofia, capítulo "Las coaliciones obreras".

24. La investigación sobre la otra estrategia y cómo pasó de tener alguna relevancia entre 1930 y 1935, en condiciones de potencial guerra civil, a diluirse en la segunda mitad de la década, aborda en profundidad esta cuestión.

25. La fundamentación de por qué considerar a 1935 como un hito en el proceso histórico está esbozada en el libro comentado (p. 56) y algo más desarrollada en Iñigo Carrera, Nicolás; "La clase obrera, la política y las armas en Argentina. 1930-1935"; en Cuadernos de Marte. Revista Latinoamericana de Sociología de la Guerra (FCSUBA); Año 4, Nº VI; enero-junio 2014; pp. 41 - 69. 
de las relaciones de fuerza operantes y, sobre todo, que sólo toma en cuenta a una pequeña porción de los obreros y desconoce a la mayor parte de la clase obrera real, su percepción de su situación y las políticas que se da para cambiarla, construyendo su propia experiencia. Al centrar la mirada en los partidos no puede explicar por qué la mayoría de los trabajadores siguió mayoritariamente una alternativa y desechó las otras. El libro lo que propone es ver las distintas alternativas, por cierto que no con un criterio clasificatorio sino distinguiéndolas con relación a lo que constituye la cuestión central: su posición respecto de la inserción en el sistema institucional. Este es un momento necesario de la investigación para poder conocer la relación entre la estrategia que se dio la mayoría de la clase obrera y las organizaciones politicas que pretendian acaudillarla.

El camino propuesto por Varela relega el papel de la relación de fuerzas objetiva y de la relación de fuerzas política en la determinación de las condiciones de un proceso revolucionario, para exagerar -y autonomizar- el papel de la voluntad. Y en eso reside el valor del comentario de Varela: poner sobre la mesa dos cuestiones, de distinta densidad teórica pero ambas importantes. La primera cuestión es la tensión entre necesidad y voluntad. En este sentido, lo que el libro afirma es que se trata de un momento de expansión capitalista en extensión, que crea mejores condiciones para el desarrollo, a partir de su experiencia de lucha previa, de una estrategia reformista de la clase obrera, conducida por las organizaciones de izquierda. No está desarrollado en el libro, porque no era el problema a investigar, que la burguesía, a diferencia de lo ocurrido en otras situaciones, encontró la manera de conducir el proceso de ciudadanización de la mayoría de la clase obrera. La segunda cuestión son los diferentes resultados a los que se arriba cuando se centra el análisis en la lucha de la clase obrera, sin reducirla a las organizaciones politicas que pretenden expresar sus intereses. En este aspecto el libro muestra la existencia de dos estrategias, una de las cuales resulta triunfante.

Queda un último punto a considerar, acerca de las "enseñanzas de la historia". El libro sí deja enseñanzas aunque Varela prefiera no verlas: en primer lugar, y aunque parezca una obviedad no lo era en el contexto en que fue escrito, confirmamos que no existen épocas sin lucha. También mostró que en los años 30 formar parte del sistema institucional no fue la única estrategia presente en la clase obrera, como sí parece serlo hoy; claro que el hecho de que existiera esa otra estrategia no la convirtió en triunfante ni siquiera en principal. Finalmente también mostró que el movimiento orgánico -que incluye sus manifestaciones politicas y culturales- tiende a imponerse sobre el movimiento ocasional.

Pero la lección más importante que podría sacarse de esta historia es 
que no hay posibilidad de triunfo de una estrategia revolucionaria que prefiera ignorar cuál es la estrategia principal o predominante de la clase obrera y el pueblo; no para hacer seguidismo sino para acompañarla en su experiencia y contribuir al desarrollo de su conciencia, generalmente reformista, y a superarla si ella se limitara a querer formar parte del sistema institucional vigente.

Diciembre de 2014 